\title{
Modulatory Effects of Cortexin and Cortagen on Locomotor Activity and Anxiety-Related Behavior in Mice
}

\author{
Walter Adriani ${ }^{*}, 1$, Oleg Granstrem ${ }^{2,3}$, Emilia Romano $^{1}$, Svetlana Koroleva $^{4}$ and Giovanni Laviola ${ }^{1}$ \\ ${ }^{I}$ Behavioral Neuroscience Section, Dept. Cell Biology \& Neurosciences, Istituto Superiore di Sanità, Rome, Italy \\ ${ }^{2}$ Dept. Neurology \& Clinic, I.P. Pavlov State Medical University, St. Petersburg, Russia \\ ${ }^{3}$ Geropharm Ltd, St. Petersburg, Russia \\ ${ }^{4}$ Department of Physiology, M.V. Lomonosov Moscow State University, Moscow, Russia
}

\begin{abstract}
Objective: Cortexin is a polypeptide extract, used in clinics for its effects on memory, attention, and brain cortical processes. A synthetic analog of one Cortexin fraction, Cortagen (i.e. Ala-Glu-Asp-Pro peptide), was developed. Both agents stimulate neural growth in vitro, presumably in association with neurotrophic factors. We assessed the psychoactive effects of Cortexin and cortagen, using elevated plus maze (EPM) and locomotor activity habituation (LAH) paradigms in CD-1 mice. In Exp. I, mice were injected with Cortexin (0, 0.25, 0.50, or $1.00 \mathrm{mg} / \mathrm{kg}$ i.p.) and tested in the EPM (acute) and the LAH (sub-chronic response). In Exp. II, separate mice were injected with cortagen $(0,0.01,0.03$, or $0.10 \mathrm{mg} / \mathrm{kg}$ i.p.) or a reference dose of Cortexin, and tested in the LAH (acute and sub-chronic) and the EPM (sub-chronic response).

Results: Evidence of anxyolitic effects was found in the EPM for acute Cortexin treatment at the 0.25 and $1.00 \mathrm{mg} / \mathrm{kg}$ dosages. The Cortexin $0.25 \mathrm{mg} / \mathrm{kg}$ was selected as reference dose for Exp. II, since it had no locomotor effects over 4 days, whilst the $1.00 \mathrm{mg} / \mathrm{kg}$ dose led to the development of hyperactivity. When comparing to Cortexin reference, the 0.03 $\mathrm{mg} / \mathrm{kg}$ dose of cortagen enhanced locomotion both upon acute and after sub-chronic treatment, also having few effects on anxiety-related behavior. Conversely, following a sub-chronic regimen (5 days), the Cortexin reference and the other doses of cortagen turned out to produce anxiogenic effects.

Conclusion: Cortexin has anxiolytic-like effects when given acutely, and anxiogenic-like arousal emerges following repeated treatment. Conversely, acute and sub-chronic cortagen leads to motor stimulation with no side effects on emotional-affective profiles. Such behavioral stimulation may find beneficial employment in the treatment of affective / depressive symptoms in humans. Peptides are active in very low dosages with no side effects, and deserve deeper investigation for their promising role in therapy.
\end{abstract}

Keywords: Elevated plus maze, locomotor habituation, behavioral pharmacology, neuropeptides.

Cortexin, a complex polypeptide extract from cerebral cortex of calves and swine, was created in Russian Military Medical Academy in 1986 and was noted for favourable effect on mnestic and cognitive functions in several patients. Today, Cortexin is considered a peptide bioregulator, and is used in the clinics for recovery of memory and attention disorders [1]. Indeed, a clinical trial with nasalelectrophoresis delivery, Cortexin produced positive modulatory effects on psycho-emotional state and on intellectual-mnestic functions [2]. Specifically, Cortexin improved attention, perception, memory, thinking, and cortical neuro-dynamic processes, as estimated in patients by quantitative parameters such as clinical symptoms, psychophysiological tests, EEG.

\footnotetext{
*Address correspondence to this author at the Section of Behavioural Neuroscience, Dept. Cell Biology \& Neurosciences, Istituto Superiore di Sanità, viale Regina Elena 299, I-00161 Roma, Italy; Tel: +39 064990 3171; Fax: +39 06495 7821; E-mail: adriani@iss.it
}

Today is known that Cortexin belongs to cytomedines, natural peptide extracts isolated from different organs that exert growth stimulating effects on cultured explants [3]. Thus, cytomedins are proposed for use in the clinical practice, in order to stimulate protective and/or reparative processes in the appropriate tissues. Moreover, these cytomedines were used as template for chemical synthesis of peptide analogues, named cytogens. Interestingly, each of these synthetic cytogens produced a stimulation of growth in explants from the specific tissue, whose cytomedin extracts were used as template [4].

Among these, Cortexin was used to produce a synthetic peptide, Cortagen (i.e. Ala-Glu-Asp-Pro), that stimulated the growth of explants specifically deriving from rat brain [4]. The effect was indeed investigated in organotypic tissue cultures of cortex and subcortical structures from 10/11-day chick embryos. Both Cortexin and Cortagen induced intensive neurite outgrowth in the cortex tissue cultures, whereas they inhibited neurite growth in the cultures from subcortical structures $[5,6]$. The neurite-outgrowth 
stimulating effect of Cortexin and Cortagen is presumably associated with release of neurotrophic factors. Recently, genomic effects of Cortagen in heart were revealed [7]. In the present paper, we investigate the psychoactive effects of both Cortexin and Cortagen in mice, using well established tests for the assessment of drug-induced locomotor arousal $[8,9]$ and anxiety-related behavior $[10,11]$. Cortexin and Cortagen were found to considerably differ, in terms of dosedependent responses, after acute $v s$ sub-chronic administration regimen.

\section{MATERIALS AND METHODS}

All experiments were formally approved by our Institute's Animal Survey Board, on behalf of the Italian Ministry of Health, and carried out in accordance with the European Communities Council Directive (86/609/EEC), and Italian Law. All efforts were made to reduce the number of animals used and to minimize their suffering.

\section{Subjects, and Rearing Conditions}

Male mice of the outbred CD-1 strain, were purchased from a commercial breeder (Charles River Italia). On arrival, mice were housed in groups of four inside Plexiglas cages $(33 \times 13 \times 14 \mathrm{~cm})$, with metal tops and a sawdust bedding. Cages were located in an air-conditioned room (temperature $21 \pm 1_{i} \mathrm{C}$, relative humidity $60 \pm 10 \%$ ), with a reversed $12-\mathrm{hr}$ light-dark cycle (lights on at 9.00 PM). Water and food (Enriched Standard Diet, Mucedola, Italy) were available ad libitum.

\section{Locomotor Activity Habituation, Apparatus and Testing}

Locomotor activity habituation (LAH) was measured in opaque-Plexiglas rectangular boxes with smooth walls and floor $(20 \times 14 \times 27 \mathrm{~cm})$. For exp. I, half of the box had black walls and white floor, whilst the other half of the box had white walls and black floor. For exp. II, both walls and floor were black in half of the box, whilst they were white in the other half of the box (black/white boxes, BWB). Each side was provided with four infrared photobeams, placed on the wall a few $\mathrm{cm}$ above the floor. The activity rate (beam interruptions per time unit) and the side preference (time spent in each side, for exp. II) were measured by a computer equipped with a specific custom-made software. Mice were gently placed in the boxes during four (exp. I) or five (exp. II) subsequent days, for a 45-min session that was automatically subdivided into three $15-\mathrm{min}$ intervals. The floor of the apparatus was cleaned after each animal and the test was carried out under dim illumination. This procedure allowed the assessment of intra- and inter-session profiles of locomotor habituation, as well as preference for the black or the slightly aversive white side (for exp. II).

\section{Elevated Plus Maze, Apparatus and Testing}

The elevated plus-maze (EPM) had two open arms (27 x $5 \times 0.25 \mathrm{~cm})$ and two closed arms $(27 \times 5 \times 15 \mathrm{~cm})$ extended from a common central platform $(5 \times 5 \mathrm{~cm})$. The apparatus was made in Plexiglas (black floor, transparent walls) and was elevated to a height of $40 \mathrm{~cm}$ above the floor level [10]. Open-arm exploration was encouraged by the inclusion of a slight raised edge $(0.25 \mathrm{~cm})$ around their perimeter. For plus- maze testing, mice were gently placed on the central platform facing a closed arm and allowed to freely explore the entire maze for a single six-min session $[12,13]$. The test was carried out under $\operatorname{dim}$ illumination and the experimenters were not present in the testing room. After each animal was tested, the plus-maze was thoroughly cleaned with wet and dry cloths. All sessions were recorded by a video-camera (positioned above at approx. $60^{\circ}$ to the maze). Videotapes were then scored by a highly-trained observer, blind to group-assignment of animals, using an ethological software (The Observer, Noldus Information Technology, The Netherlands). The following behavioral measures were obtained: 1) latency to enter each arm; 2) number of entries in each arm;3) time spent in each arm;4) head dipping; 5) stretched attend postures (SAP); 6) rearing.

\section{Chromatographic Analysis}

For Cortexin and Cortagen characterization, the size exclusion HPLC method was used, with Gel-Filtration consisting of an Insulin HMWP column 300 x 7,8 mm (Waters Corporation, Milford, MA, USA). Elution was performed in isocratic conditions $\left(\mathrm{CH}_{3} \mathrm{COOH}\right.$ : acetonitrile: $0.1 \%$ arginine solution, 15:20:65 correspondingly) with flow rate of $0.5 \mathrm{ml} / \mathrm{min}$ at room temperature. Detection was then performed at $276 \mathrm{~nm}$. Integration time was set up as $0.1 \mathrm{sec}$.

\section{Drugs, Design, and Statistics}

The natural polypeptide extract Cortexin (Geropharm Ltd, Russia) and the synthetic peptide Cortagen (patented in Russia, (19)RU(11)2155063(13)C1, supported in the EU and the USA) [14] were dissolved in saline (SAL) and injected i.p. at least fifteen minutes before the behavioural tests. Two separate batches of mice were used. For the experiment I, mice were randomly assigned to be tested with one of four Cortexin dosages $(0,0.25,0.50,1.00 \mathrm{mg} / \mathrm{kg})$. Mice first underwent the EPM, 15 min after acute Cortexin, and then $\mathrm{LAH}$, to evaluate acute and sub-chronic response profiles. For the experiment II, mice were randomly assigned to be tested with one of three cortagen dosages $(0,0.01,0.03,0.10$ $\mathrm{mg} / \mathrm{kg})$, or a selected Cortexin dose $(0.25 \mathrm{mg} / \mathrm{kg})$. Mice first underwent $\mathrm{LAH}$, to evaluate acute and sub-chronic response profiles, and then the EPM, 24h after the last injection of Cortexin / cortagen.

Data were analyzed with ANOVA, the design of the experiments being a treatment dose $\mathrm{x}$ repeated measure factors model. Level of significance was set at $\mathrm{p}<0.10$, as the range $.05<\mathrm{p}<.10$ was specifically taken as indicating a significant tendency. Multiple comparisons were then performed by the Tukey HSD test when allowed.

\section{RESULTS}

\section{Experiment I: Anxiety-Related Behavior in the EPM}

The ANOVA carried out for latency to enter open arms yielded tendency for dose effect, $\mathrm{F}(3,31)=2.095, .05<\mathrm{p}<$ .10; The post hoc comparisons revealed a significantly lower latency for the $0.25 \mathrm{mg} / \mathrm{kg}$ group to enter open arms, compared to SAL control. The ANOVA for time spent in open arms yielded an effect for dose, $\mathrm{F}(3,31)=3.851$, $\mathrm{p}<$ .05 ; The post hoc comparisons revealed that both the .25 and the $1.00 \mathrm{mg} / \mathrm{kg}$ groups spent much more time into the open 
arms, compared to controls. This piece of data (Fig. 1, left panel) indicates enhanced exploration of non protected arms.

The ANOVA for frequency of entries in the open arms yielded significant main effect for dose, $F(3,31)=14.034, p<$ $0.001)$. The post hoc comparisons confirmed a significantly higher level of open-arm entries $(\mathrm{p}<.05)$ for the Cortexin $0.25 \mathrm{mg} / \mathrm{kg}$ group $(9.44 \pm 1.51)$, compared to SAL controls $(2.37 \pm 0.91)$ and to the other two Cortexin dosages. This picture supports robust anxiolytic action of Cortexin at the $0.25 \mathrm{mg} / \mathrm{kg}$ dosage. A similar although less robust tendency also emerged for mice treated with the $1.00 \mathrm{mg} / \mathrm{kg}$ dose.

The ANOVA for frequency to enter closed arms yielded no effect for dose, $\mathrm{F}(3,31)=1.401$, NS; Data indicate a frequency of $11.8 \pm 1.3,13.7 \pm 1.4,11.3 \pm 0.7,10.7 \pm 1.1$ entries for Cortexin $0,0.25,0.50$ and $1.00 \mathrm{mg} / \mathrm{kg}$, respectively. Post hoc comparisons confirmed no significant differences among groups, thus indicating that general locomotion was unaffected. Differences shown in open-arm exploration do not appear to be biased by hypo- or hyperactivity profiles. ANOVAs for rearing yielded a tendency for dose effect, $\mathrm{F}(3,31)=1.965, .05<\mathrm{p}<.10$; Post hocs revealed a significantly lower level of rearing for the 1.00 $\mathrm{mg} / \mathrm{kg}$ group compared to SAL controls (data not shown).

The ANOVA for frequency of head dipping yielded no effect for dose, $F(3,31)=0.351$, NS; The post hoc comparisons confirmed no significant differences among groups thus indicating that general exploration of animals was unaffected by Cortexin. The ANOVA for frequency of the stretched-attend posture (SAP), a reliable index of assessment for potential environmental risks, yielded an effect for dose, $\mathrm{F}(3,31)=4.293, \mathrm{p}<.05$; The post hoc comparisons revealed that the groups treated with the .25 and the $1.00 \mathrm{mg} / \mathrm{kg}$ dosages were much less involved in this behavior, compared to controls. This robust finding (Fig. 1,

\section{ANXIETY-RELATED BEHAVIOR}

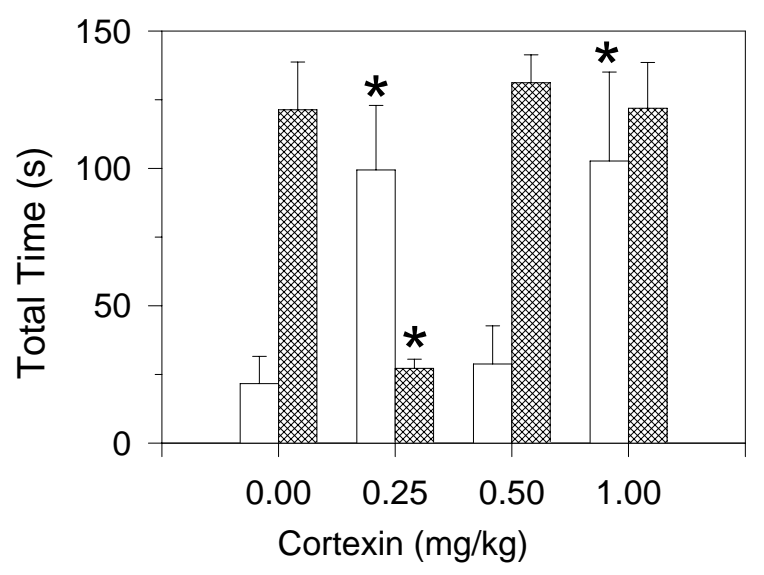

Open Arms: $\square$ Exploration Latency to Enter right panel) indicates a low expression of anxiety-induced risk-assessment postures, supporting increased disinhibition.

\section{Experiment I: Locomotor Activity Habituation (LAH)}

In the first experiment, the effects of Cortexin injection were absent during the first two days. In fact, the ANOVA carried out on first and second day of injection yielded no significant effects of dose. A main effect of dose, $F(3,24)=$ $2.41, .05<\mathrm{p}<.10$, appeared in the ANOVA carried out on third and fourth day of injection (Fig. 2). Multiple comparisons confirmed that, on both days, a significant reduction of activity levels was shown by mice injected with the $0.50 \mathrm{mg} / \mathrm{kg}$ dose, compared to SAL controls. On the other hand, mice injected with the $1.00 \mathrm{mg} / \mathrm{kg}$ dose showed significantly higher activity levels than SAL controls. These data indicate for Cortexin the development of a biphasic locomotor effect: a motor sedation emerges at $0.50 \mathrm{mg} / \mathrm{kg}$, whereas the $1.00 \mathrm{mg} / \mathrm{kg}$ dose leads to a hyper-arousal profile over subsequent administration sessions.

In summary, the most convincing evidence of anxyolitic effects is found for mice treated with the 0.25 and 1.00 $\mathrm{mg} / \mathrm{kg}$ dosages, which consistently exhibited a shorter latency to enter the open arms, spent much more time into them, together with a low level of anxiety-induced riskassessment postures. General parameters of locomotion and exploration were unaffected by Cortexin in the EPM. The $0.25 \mathrm{mg} / \mathrm{kg}$ dose of Cortexin was then selected as a reference for the second experiment since it had no effects on locomotion, at least over 4 days of repeated treatment.

\section{Experiment II: Locomotor Activity Habituation (LAH)}

Locomotor activity in the second experiment confirmed the effects of Cortexin and provided novel information on cortagen. From the general analysis, conducted on the

\section{RISK ASSESSMENT}

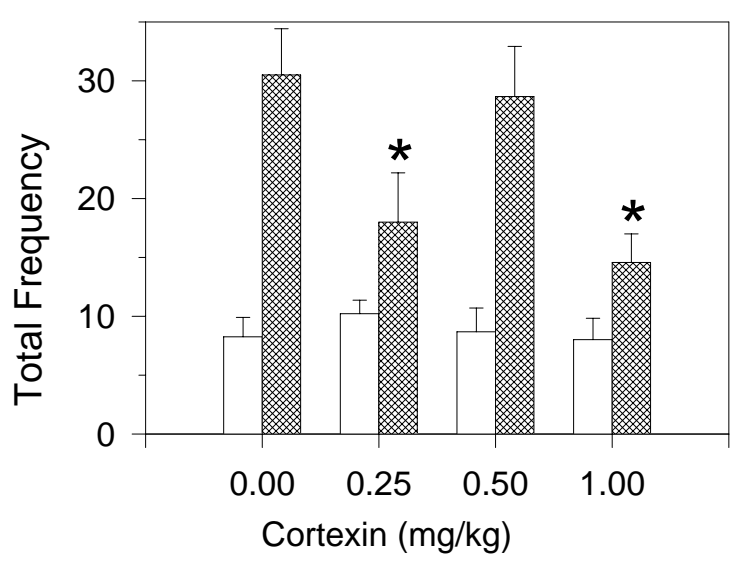

\section{Head Dipping 桨怒 Stretched Attend Posture}

Fig. (1). Time (s) spent in open-arm exploration and latency (s) to enter the open arm (left panel); Frequency (total number of episodes) for head dipping and stretched attend posture (right panel). Animals were injected, 15 min before being placed in the plus maze, with Cortexin $(0,0.25,0.50$ and $1.00 \mathrm{mg} / \mathrm{kg}) .{ }^{*} \mathrm{p}<.05$ compared to control group $(\mathrm{n}=8)$. 
locomotor activity data from both the first day and the last day of treatment, it appears that both Cortexin and Cortagen (when administered at the $0.03 \mathrm{mg} / \mathrm{kg}$ dose) are able to induce an increase of locomotor activity, compared with control mice. However, the treatment factor was statistically significant only in interaction with the repeated measures (day and time) factors, $\mathrm{F}(8,70)=2,59, \mathrm{p}<.05$. For this reason, two analyses were conducted separately for the first and the last day of treatment.

The analysis of data from the first day (i.e. acute effects, Fig. 3, left panel) revealed an interaction of treatment with time, $F(8,70)=6,35, p<.05$. Post hocs reveal that only the 0.03 dose of Cortagen produced, as an acute effect, an increase of locomotor activity compared to the control group. In particular, the $0.03 \mathrm{mg} / \mathrm{kg}$ dose of Cortagen was specifically associated with high and constant elevation of activity throughout the test session, while the other doses of Cortagen and the Cortexin did not show any effects.

Following the sub-chronic treatment (Fig. 3, right panel), data reveal an effect of treatment in interaction with time $\mathrm{F}(8,70)=1,53, .05<\mathrm{p}<.10$. In particular, mice administered either the $0.03 \mathrm{mg} / \mathrm{kg}$ dose of Cortagen or Cortexin showed higher levels of locomotor activity, compared to the control group. There are no observed effects for the other two Cortagen doses. It can be concluded that, in contrast to what happens for Cortagen, which is already acting following an acute administration, Cortexin requires at least five days of sub-chronic administration to carry-out its locomotor effects.

\section{LOCOMOTOR ACTIVATION}

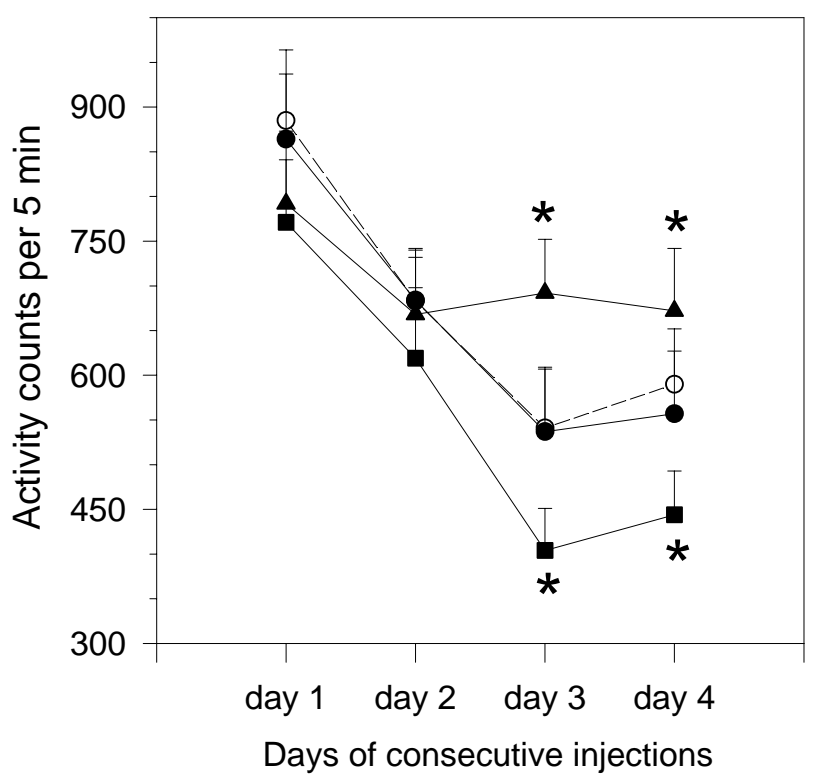

Fig. (2). Locomotion (number of beam interruptions per $5 \mathrm{~min}$ ) measured within the 2-side activity boxes during 45-min sessions on four subsequent days. Animals were injected, $15 \mathrm{~min}$ before sessions, with Cortexin (white circle $=0 \mathrm{mg} / \mathrm{kg}$, black circle $=0.25$ $\mathrm{mg} / \mathrm{kg}$, black square $=0.50 \mathrm{mg} / \mathrm{kg}$, black triangle $=1.00 \mathrm{mg} / \mathrm{kg}$ ). $*$ $\mathrm{p}<.05$ compared to control group $(\mathrm{n}=8)$.

\section{LOCOMOTION, Day 1}
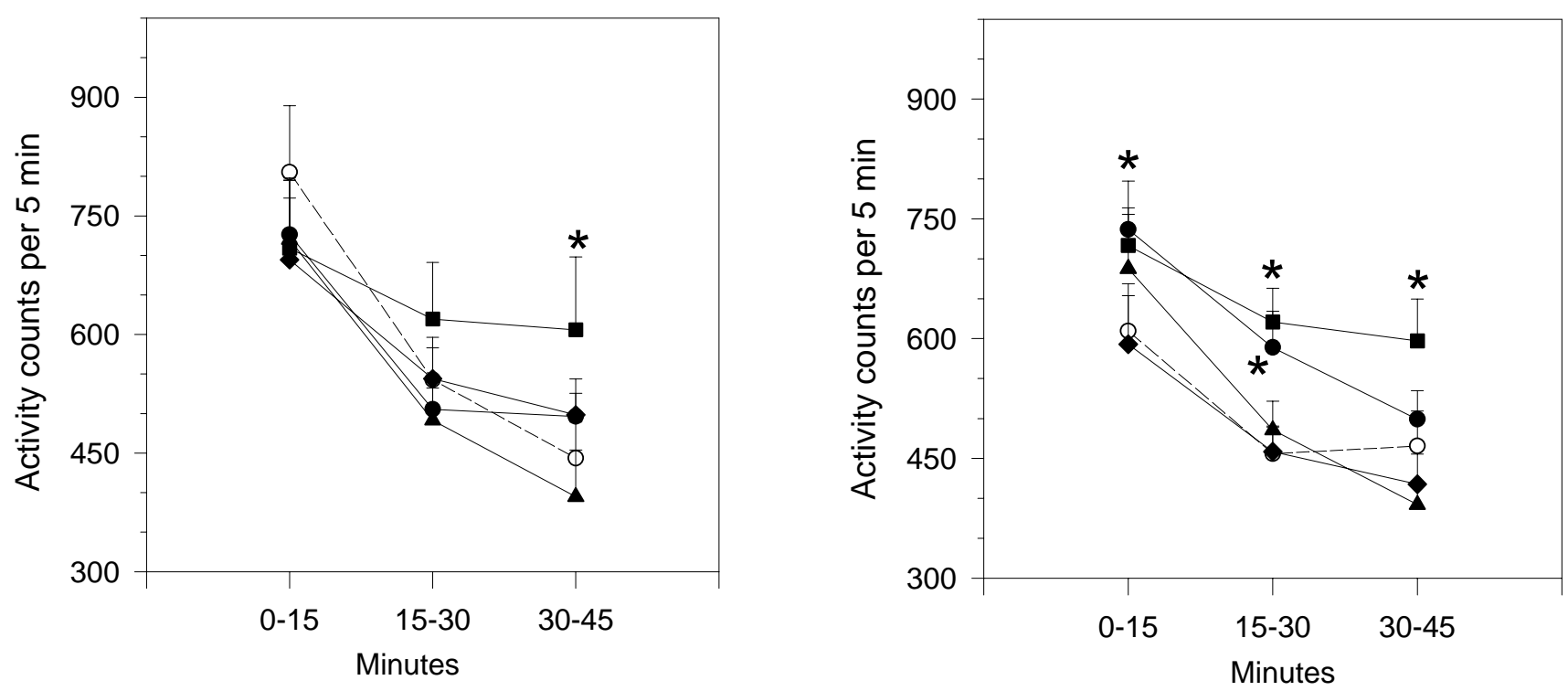

Fig. (3). Locomotion (number of beam interruptions per $5 \mathrm{~min}$ ) measured within the 2-side activity boxes during 45-min session on first (left panel) and fifth (right panel) day of treatment. Animals were injected, $15 \mathrm{~min}$ before the session, with the assigned drug (Control, white circle; Cortexin $0.25 \mathrm{mg} / \mathrm{Kg}$, black circle; Cortagen: black rhombi $0.01 \mathrm{mg} / \mathrm{kg}$, black square $0.03 \mathrm{mg} / \mathrm{kg}$, black triangle $0.10 \mathrm{mg} / \mathrm{kg}$ ). ${ }^{*} \mathrm{p}$ $<0.05$ compared to control group $(\mathrm{n}=8)$. 


\section{Experiment II: Anxiety-Related Behavior (BWB; EPM)}

The general analysis, conducted on time spent in the white compartment of the BWB testing, revealed a tendency of mice administered 0.01 and $0.1 \mathrm{mg} / \mathrm{kg}$ doses of Cortagen to spend less time in this slightly-aversive side than the control group. We proceeded with two separate analyses, on day 1 and 5 , to assess the effects of acute and sub-chronic treatment, respectively.

The analysis for the first day (acute treatment, see Fig. 4, white bars) revealed an effect of treatment by time, $F(8,70)=$ $2,59, .05<\mathrm{p}<.10$. Post hoc analyses showed that Cortexin increases the time spent in the white compartment, compared to control group, suggesting an anxiolytic effect. In contrast, the 0.01 (and the 0.1 to a lesser extent) $\mathrm{mg} / \mathrm{kg}$ doses stimulated mice to spend more time in the black compartment, compared to control group, suggesting an anxiogenic profile.

The analysis of the fifth day (sub-chronic treatment, see Fig. 4, black bars) showed an effect of treatment by time, $\mathrm{F}(8,68)=7,10, \mathrm{p}<.05$. Post hoc analyses revealed that, following a sub-chronic treatment, Cortexin reduces significantly the time spent in the white side, compared to controls, suggesting the production of an anxiogenic profile. This finding is noteworthy, because acute Cortexin was indeed anxiolytic. In contrast, the 0.1 (and 0.01 to a lesser extent) $\mathrm{mg} / \mathrm{kg}$ doses of Cortagen showed an anxiogenic effect. In other words, sub-chronic Cortagen continues to exert the same effects as it was observed upon acute administration, with no evidence for development of a tolerance or a sensitization profile.

Animals were then tested in the EPM apparatus $24 \mathrm{~h}$ after the last drug injection. ANOVAs just failed to reach significance for some parameters (which are shown in Table 1), while no effect of the dose factor emerged for other variables like open-arm entries (frequency \& latency) and other behaviors (i.e. rearing \& head dipping). Interestingly, a significant reduction of stretched attend postures (SAP) was observed in the EPM for all Cortagen dose groups. Multiple comparisons revealed also a reduction of time spent in the open arm by mice repeatedly treated with Cortagen 0.01 $\mathrm{mg} / \mathrm{kg}$, and an increase in the closed-arm entries by Cortagen $0.03 \mathrm{mg} / \mathrm{kg}$ mice. These data do confirm the profile already obtained in the activity boxes (see above for LAH on day 1 and 5), in that they support an anxiogenic effect by the 0.01 $\mathrm{mg} / \mathrm{kg}$ dose of Cortagen, and higher levels of locomotor activity by the $0.03 \mathrm{mg} / \mathrm{kg}$ dose of Cortagen.

Conversely, no carry-over effects of sub-chronic Cortexin were shown on the EPM, which was carried out in drug-free condition $24 \mathrm{~h}$ after last injection. This piece of data actually suggests that, whilst Cortexin effects disappeared rapidly when treatment was discontinued, enduring carry-over consequences were produced by Cortagen on the behavioral repertoire, as also suggested by the slight reduction of outward risk-evaluation postures at all doses.

\section{DISCUSSION}

It can be summarized that Cortexin had anxiolytic-like effects when administered acutely whilst, after a sub-chronic

\section{PERMANENCE IN THE WHITE SIDE}
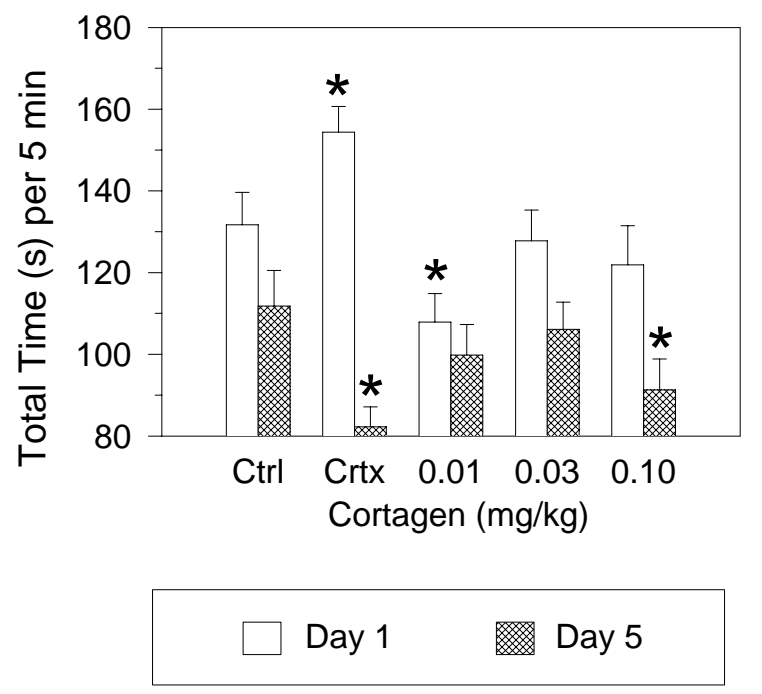

Fig. (4). Time (s) spent in the white compartment of the 2-side black/white boxes (BWB) on first (white bars) and fifth (black bars) day of treatment. Animals are the same as in Fig. (3), i.e. Control (Ctrl); Cortexin (Crtx); Cortagen (three doses). ${ }^{*} \mathrm{p}<0.05$ compared to control group $(\mathrm{n}=8)$.

treatment, it turned out to enhance both locomotor activity levels and anxiety-related behaviors. This sub-chronic effect may well be defined as a psychostimulant-like sensitization [8], since a classical and potent psychostimulant, amphetamine, is well known to trigger both locomotor hyperactivity and anxiogenic effects [15]. Cortexin can indeed reach the nigro-striatal dopaminergic system [16], a major target of psychostimulants that takes part in organization and regulation of motor functions. Cortexin has been also studied in Wistar rats after intra-ventricular injection and, accordingly, a moderate psycho-stimulant and/or a moderate anxiolytic action were produced [17, 18]. More direct comparisons with present study are however difficult, because of different species and administration route.

As for Cortagen, the $0.03 \mathrm{mg} / \mathrm{kg}$ dose renders a nice stimulation on locomotor activity, both in acute and after a sub-chronic treatment, and does not show any effect on emotional state. Conversely, lower and higher doses of Cortagen induce an anxiogenic-like effect, both in acute and after a sub-chronic treatment. These dosages do not show any effect on locomotor activity, and tend to persist after treatment discontinuation. Thus, the specific $0.03 \mathrm{mg} / \mathrm{kg}$ dose of Cortagen is worth to be further explored for possible applications in therapy.

So far, no specific receptors and/or pathways have been discovered, mediating Cortexin and/or Cortagen effects. Pharmacology and pharmacokinetics of these compounds remain unclear yet, mainly due to methodological difficulties linked with their peptide nature and very low effective doses. Cortexin is a complex of oligopeptides isolated from brain cortex of calves and swines, and is comparable to a multivalent drug. Cortagen was intentionally constructed, based on the amino-acid formula analysis of peptide 
Table 1. Anxiety-Related and Risk-Assessment Behavior in the EPM (Experiment 2)

\begin{tabular}{|l|c|c|c|}
\hline & Time Spent in the Open Arms (s) & Entries in Close Arm & SAP Frequency \\
\hline \hline Control & $104.49 \pm 13.93$ & $15.75 \pm 1.03$ & $15.0 \pm 1.96$ \\
\hline Cortexin & $105.16 \pm 9.64$ & $16.75 \pm 1.71$ & $14.88 \pm 1.41$ \\
\hline Cortagen 0.01 & $83.46^{*} \pm 10.46$ & $15.88 \pm .95$ & $10.50 \pm 1.81^{*}$ \\
\hline Cortagen 0.03 & $100.63 \pm 17.48$ & $18.50 \pm 1.57^{*}$ & $9.88 \pm 2.20^{*}$ \\
\hline Cortagen 0.1 & $105.80 \pm 10.29$ & $17.88 \pm 2.45$ & $11.28 \pm 1.87$ \\
\hline
\end{tabular}

Time (s) spent in open-arm exploration; Frequency for closed-arm entries; Frequency for stretched attend posture (SAP). Animals were injected, for 5 consecutive days, with a reference Cortexin $(0.25 \mathrm{mg} / \mathrm{kg})$ dose, or with Cortagen $(0,0.01,0.03$ or $0.10 \mathrm{mg} / \mathrm{kg})$. Animals were exposed to the plus maze, $24 \mathrm{~h}$ after the last drug injection. * $\mathrm{p}<.05$ compared to control group $(\mathrm{n}=8)$.

fractions isolated from total Cortexin preparation [16]. Chromatograms presented on Fig. (5) demonstrate that Cortagen peaks are included in the Cortexin continuum. The double peak for pure compound under size-exclusion chromatography could be explained by different states of counter ion (acetate) dissociation.

Special attention should be payed to the fact that Cortagen consists of a small number (four) of amino-acid residues. According to the literature data on regulatory peptides (RP), the structures with a length of about 10 amino-acid are the most numerous and active RP-types. Cortagen can be compared to similar bioactive peptide, for example to Epitalon [19] and/or Vilon [20], to find a common spectrum of activity. Based on our experimental data, it is possible to propose two tentative mechanisms of Cortagen and Cortexin bioactivity.

\section{Psycho-Pharmacological Profile of Cortagen}

Previous experiments and literature data have shown a range of properties for Cortagen [21], including stimulation of CNS neurons, antioxidant activity, reduction of drug toxicity, and activation of reparative processes. Here, we evaluated three main behavioral domains: anxiety-related behavior, orienting-exploratory reactions, and locomotor activity.

Experimental data with Cortagen show a combined profile of psycho-physiological activity in mice. At doses of 0.01 and $0.1 \mathrm{mg} / \mathrm{kg}$, Cortagen did not affect locomotor activity. At the same time, however, peptide administration at these two doses resulted in a slight anxiogenic effect, that was observed either acutely or sub-chronically, i.e. upon first or the fifth administration, respectively. On the other hand, at the intermediate dose of $0.03 \mathrm{mg} / \mathrm{kg}$, locomotor activity was elevated when administered both acutely and sub-chronically (once/day for 5 days), but no anxiogenic effect was observed. It is noteworthy that, within this dose range, there is a consistent $\mathrm{U}$-shaped transition in the profile of effects. Indeed, anxiety-related profiles were the opposite in relation to motor activity, with the intermediate dose representing a "transition point" compared to lower and higher ones.

These Cortagen-induced anxiogenic and arousing profiles cannot be defined by a unidirectional impact of the dosage,
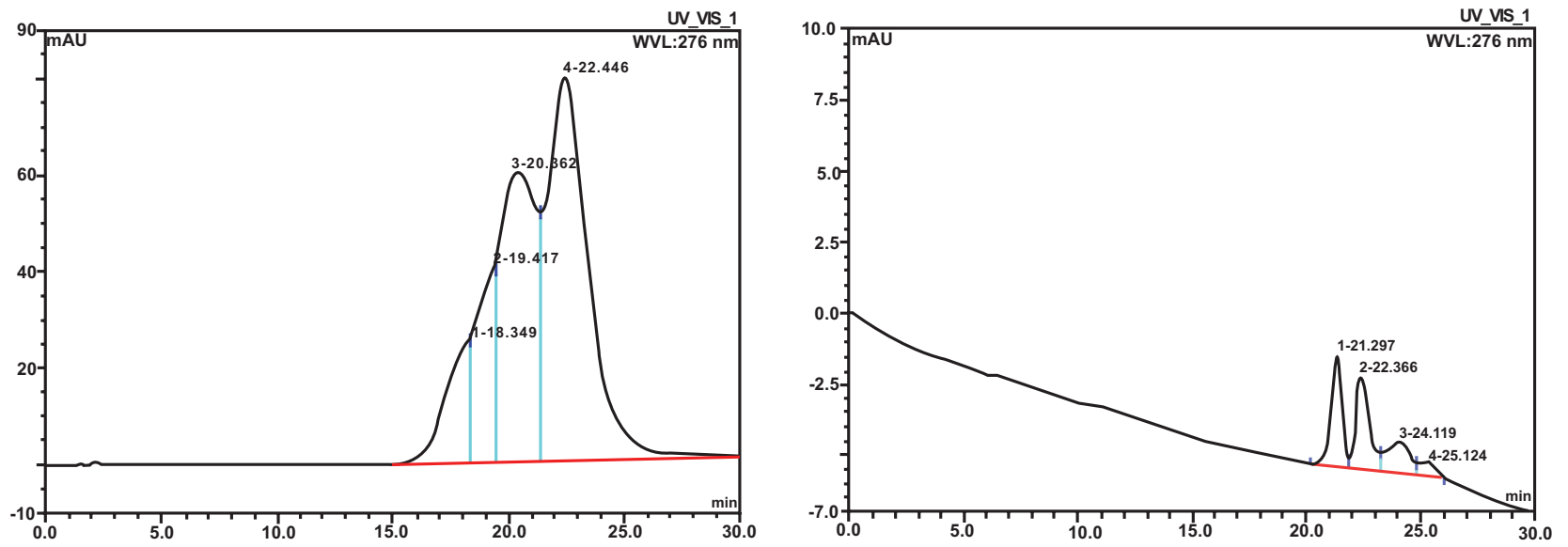

\begin{tabular}{|c|c|c|c|c|c|c|c|}
\hline No. & Ret.Time & Peak Name & Height & Area & Ref. Are & Amount & Type \\
\hline & $\min$ & & MAU & mAU'min & $\%$ & $\mathrm{mg} / \mathrm{ml}$ & \\
\hline 1 & 18.35 & n.a & 25.340 & 29.953 & 8.92 & n.a. & $M^{*}$ \\
\hline 2 & 19.42 & n.a & 40.756 & 35.362 & 10.54 & n.a. & $M^{*}$ \\
\hline 3 & 20.36 & n.a & 60.027 & 108.472 & 32.32 & n.a. & $M^{*}$ \\
\hline 4 & 22.45 & n.a & 79.623 & 161.864 & 48.22 & n.a. & $\mathrm{MB}^{*}$ \\
\hline Total: & & & 205746 & 335651 & 10000 & 0.000 & \\
\hline
\end{tabular}

\begin{tabular}{|c|c|c|c|c|c|c|c|}
\hline No. & $\underset{\text { min }}{\text { Ret.Time }}$ & PeakName & $\begin{array}{l}\text { Height } \\
\text { mAU }\end{array}$ & $\begin{array}{c}\text { Area } \\
\text { mAU'min }\end{array}$ & $\begin{array}{c}\text { Rel.Area } \\
\%\end{array}$ & $\begin{array}{c}\text { Amount } \\
\mathrm{mg} / \mathrm{ml}\end{array}$ & Type \\
\hline 1 & 21.30 & n.a. & 3.938 & 2.271 & 36.68 & n.a. & $\mathrm{BM}^{*}$ \\
\hline 2 & 22.37 & n.a. & 3.275 & 2.242 & 36.22 & n.a. & $\mathrm{M}^{*}$ \\
\hline 3 & 24.12 & n.a. & 1.114 & 1.265 & 20.44 & n.a. & $\mathrm{M}^{*}$ \\
\hline 4 & 25.12 & n.a. & 0.518 & 0.412 & 6.66 & n.a. & $\mathrm{MB}^{*}$ \\
\hline Total: & & & 8.845 & 6.190 & 100.00 & 0.000 & \\
\hline
\end{tabular}

Fig. (5). Size exclusion HPLC chromatography of Cortexin (A) and Cortagen (B) samples (from Geropharm Ltd., St Petersburg, Russia). Sampling: Cortexin - pharmaceutical composition from Russian market; Cortagen - synthetic peptide in form of acetate salt (purity: $97 \%$ by HPLC). 
since they followed opposite and U-shaped profiles. Such complex of dose-dependent reactions can perhaps be accounted by the combination of two different processes. Two target systems of different nature (with different molecular regulatory patterns) might have separate "active" dose-effect ranges. One process, anxiogenic-related effects, is produced at a wider range of doses (including 0.01 and $0.10 \mathrm{mg} / \mathrm{kg}$ ), while the other process, hyperarousal, is generated with a narrower range at the specific $0.03 \mathrm{mg} / \mathrm{kg}$ dosage. Then, if we overlap the vectors of these two processes, it is possible to account for the observed combination of motor/anxiogenic reactions: 1) increased level of anxiety (with no motor signs) at 0.01 and again at $0.1 \mathrm{mg} / \mathrm{kg}$, and 2) motor stimulation at $0.03 \mathrm{mg} / \mathrm{kg}$ (with a marked reduction of signs deriving from the former anxiogenic process). Bell-shaped "dose-effect" curves are indeed typical for peptides [22].

It is possible to hypothesize that, at a dose of $0.03 \mathrm{mg} / \mathrm{kg}$, a motivated exploratory drive is released and thus Cortagen normalizes the emotional balance. On the other hand, at doses of 0.01 and $0.1 \mathrm{mg} / \mathrm{kg}$, increased anxiety-related behaviors can become manifest due to the lack of a true outward-directed exploration. Noteworthy then, Cortagen induced the intensification of locomotion, an index of exploratory motivation and outward activity [12], which appears to overcome (or to mask) the drug-induced aversive reactions inside the black/white box (BWB) test.

\section{Psycho-Pharmacological Profile of Cortexin}

The profile of effects for the various doses of Cortexin in mice is rather complex. However, the responses to Cortexin can be divided into two main types: 1) a "transition" point at a specific dose $(0.50 \mathrm{mg} / \mathrm{kg}) ; 2)$ "accumulation", i.e. sensitization and its manifestation, at doses of 0.25 and 1.0 $\mathrm{mg} / \mathrm{kg}$. We would like to emphasize that Cortexin is a complex multi-agent mixture, and each of its elements may therefore act by tapping onto a different regulatory system.

Transition. At the specific dosage of $0.50 \mathrm{mg} / \mathrm{kg}$, Cortexin does not affect the anxiety-related parameters at all (as it was conversely evident for lower and higher doses), but decreases locomotor activity when administered subchronically for 3-4 days. The specificity of Cortexin at a 0.50 $\mathrm{mg} / \mathrm{kg}$ dose is to some extent similar to the Cortagen effect at a $0.03 \mathrm{mg} / \mathrm{kg}$ dose. In contrast to Cortagen, locomotor activity is decreased by Cortexin. However, by the recruitment of a targeted motivational and/or exploratory system, a final status is attained where the emotional aspects are balanced and not prevailing, i.e. with no anxiolytic nor anxiogenic effects.

Accumulation. When administered acutely at 0.25 $\mathrm{mg} / \mathrm{kg}$, Cortexin exerts a marked anxiolytic effect in the EPM: short latency and enhanced frequency to enter open arms, much more time spent within the open arms, together with reduced risk-evaluation postures (like SAP). Despite a potential danger, mice faced the risk of falling by increased head dipping, an orienting-exploratory activity [12]. At the same time, no influence at all was exerted on general locomotor activity (as measured by closed arm entries in the EPM or locomotion in the activity boxes). This piece of data implies that acute administration of Cortexin induced a condition of emotional dishinibition. Namely, the repertoire consisted of enhanced curiosity-driven exploratory activity, and conversely the risk-evaluating processes and the anxietyinduced behavioral reactions were strongly reduced.

However, following sub-chronic administration, an inversion of all listed reactions occurs: on fifth day, anxietyrelated behaviors increase and locomotor activity arises. In this case, the arousal was not due to increased motivation for outward exploration, as in the case of Cortagen. Rather, Cortexin-induced hyperactivity can be described in association to the stress elicited by the drug-induced anxiogenic effects, similarly to amphetamines [15]. In other words, some "defensive" exploratory reactions are brought to the fore by the altered emotional profile.

At $1.0 \mathrm{mg} / \mathrm{kg}$, profiles are similar to those produced by the $0.25 \mathrm{mg} / \mathrm{kg}$ dosage: an anxiolytic effect again occurs acutely, with the subsequent development of sensitized locomotion after a sub-chronic regimen. In particular, after accumulating many daily sub-threshold effects, the extent (or the rapidity) of the locomotor sensitization influenced by Cortexin is dose-dependent: at $1.0 \mathrm{mg} / \mathrm{kg}$, arousal emerged already by the $3^{\text {rd }}$ day, while two more injections were needed (as it came out only by the $5^{\text {th }}$ day) at $0.25 \mathrm{mg} / \mathrm{kg}$. It is perhaps likely that the development of such a sub-chronic sensitization exploits a similar molecular pathway for both doses.

\section{CONCLUSION}

In brief, compared to the specific effects of a given "transition" dose (i.e. $0.50 \mathrm{mg} / \mathrm{kg}$ for Cortexin; $0.03 \mathrm{mg} / \mathrm{kg}$ for Cortagen), other lower or higher doses do exert very different exploratory $v s$ affective consequences, especially following the accumulation of repeated daily challenges (i.e., at 0.25 or $1.00 \mathrm{mg} / \mathrm{kg}$ for Cortexin; at 0.01 or $0.10 \mathrm{mg} / \mathrm{kg}$ for Cortagen). These two separate pictures are possibly associated with responses of different (e.g. motivational vs emotional) systems.

Our results suggest indeed that Cortagen and Cortexin affect behavior in a bell-shaped dose-dependent manner, with a dosage-specific effect (termed "transition") at 0.03 $\mathrm{mg} / \mathrm{kg}$ or $0.50 \mathrm{mg} / \mathrm{kg}$, respectively, i.e. a typical range of concentrations for biologically active peptides. Cortagen and Cortexin at the lower and higher dosages may tap onto (an)other target system(s). We also propose that a subchronic regimen of accumulating daily administration may trigger sensitization, i.e. the building-up of neurochemical adaptations then followed by a final manifestation, which depend on the dose-targeted system. Such "accumulation" similarly differs in nature depending on the dose (e.g., compare the primarily-emotional sensitization, by 0.25 $\mathrm{mg} / \mathrm{kg}$ Cortexin and by $0.10 \mathrm{mg} / \mathrm{kg}$ Cortagen, with mainlylocomotor sensitization, at $0.50 \mathrm{mg} / \mathrm{kg}$ Cortexin and 0.03 $\mathrm{mg} / \mathrm{kg}$ Cortagen). Possibility for peptides to change their regulatory contours, showing "transition" dosages with their own "accumulation" profile that strikingly differs from lower or higher dosages, is confirmed by many data nowadays $[23,24]$.

Summing up, we would like to emphasize that the putative mechanisms of action for these two peptide drugs are crucially different. As is the case for an integrative signal compared to one of its solitary-subsystem fractions, Cortexin 
is a variable multi-target drug whilst Cortagen is a more efficient regulatory vector (though one includes the other). It is necessary to further evaluate (and compare) their effects and side consequences, possibly by more complex approaches in pre-clinical models $[25,26]$. It is worth trying to better define advantages of either medicine for potential treatment of neuro-psychiatric pathology: Peptides are suitable drugs in the diseased organism, due to reduced side effects and lower dosages [27]. Further studies are warranted to better estimate potential of peptide drugs in several areas of therapeutic application.

\section{ACKNOWLEDGEMENTS}

This work was supported by Geropharm Ltd., Russia; partially supported by the "ADHD-sythe" project ("under40" call 2007), Italian Ministry of Health (to W.A.); by the bilateral Italy-USA Program on Rare Diseases (7NR1), and by the ERARE-EuroRETT (ERAR/6) Network (to G.L.); by NATO Reintegration Grant No. 981199, and by ISNI Program "Aid for Neuro-chemistry" (to O.G.). A student fellowship was also granted (to E.R.) by the European Mind \& Metabolism Association (EMMA). We are grateful to four talented high-school students (Andrea BUSCAIONI, Giancarlo LAURETTI, Federico ZANIN, Giulia OLYFF) for precious assistance with behavioral scoring. There is no conflict of interest to disclose.

\section{REFERENCES}

[1] Tsygan VN, Bogoslovskii MM. Influence of Cortexin on memory and attention [Russian]. Voen Med Zh 2004; 325: 31-5.

[2] Khavinson VK, Morozov VG, Rybnikov VIu, Zakutskii NG. Cortexin effectiveness in circulatory encephalopathy. Klin Med (Mosk) 1999; 77: 42-5.

[3] Chalisova NI, Khavinson VK. Studies of cytokines in nerve tissue cultures. Neurosci Behav Physiol 2000; 30: 261-5.

[4] Khavinson VK. Tissue-specific effects of peptides. Bull Exp Biol Med 2001; 132: 807-8.

[5] Khavinson VK, Morozov VG, Chalisova NI, Okulov VB. The effect of brain peptides on nerve tissue cells in vitro. Tsitologiia 1997; 39: 571-6.

[6] Chalisova NI, Khavinson VKh, Davydenko VV, Dorovskii AA, Verbovaia TA, Penniiainen VA. Effect of cytomedins on development of organotypic culture of various tissues from the internal organs of rats. Tsitologiia 2000; 42: 1144-7.

[7] Anisimov SV, Khavinson VK, Anisimov VN. Elucidation of the effect of brain cortex tetra-peptide Cortagen on gene expression in mouse heart by microarray. Neuroendocrinol Lett 2004; 25: 87-93.

[8] Stewart J, Badiani A. Tolerance and sensitization to the behavioral effects of drugs. Behav Pharmacol 1993; 4: 289-312.

[9] Tirelli E, Laviola G, Adriani W. Ontogenesis of behavioral sensitization and conditioned place preference induced by psychostimulants in lab rodents. Neurosci Biobehav Rev 2003; 27: 163-78.

[10] Holmes A, Rodgers RJ. Influence of spatial and temporal manipulations on the anxiolytic efficacy of chlordiazepoxide in mice previously exposed to the elevated plus-maze. Neurosci Biobehav Rev 1999; 23: 971-80.
[11] Laviola G, Macri' S, Morley-Fletcher S, Adriani W. Risk-taking behavior in adolescent mice: Psychobiological determinants and early epigenetic influence. Neurosci Biobehav Rev 2003; 27: 1931.

[12] Macrì S, Adriani W, Chiarotti F, Laviola G. Risk-taking during exploration of a plus-maze is greater in adolescent than in juvenile or adult mice. Anim Behav 2002; 64: 541-6.

[13] Adriani W, Granstrem O, Macri' S, Izykenova G, Dambinova S, Laviola G. Behavioral and neurochemical vulnerability during adolescence in mice: Studies with nicotine. Neuropsychopharmacology 2004; 29: 869-78.

[14] Khavinson VK, Morozov VG, Malinin VG, Grigoriev EI. Tetrapeptide stimulation on functional activity of neurones, pharmacological agent based thereon and method of use thereof. [patents] WO/2001/029067, PCT/RU2000/000218.

[15] Cancela LM, Basso AM, Martijena ID, Capriles NR, Molina VA. A dopaminergic mechanism is involved in the 'anxiogenic-like' response induced by chronic amphetamine treatment: a behavioral and neurochemical study. Brain Res 2001; 909: 179-186.

[16] Skoromets AA, Dyakonov MM. Cortexin-Five years in neurological practice in Russia. Saint-Petersburg: Nauka Publishing House 2007; p. 224.

[17] Shabanov PD, Lebedev AA, Stetsenko VP, Lavrov NV, Markov SV, Vojeikov IV. Comparison of behavioral effects of cortexin and cerebrolysin injected into brain ventricles. Bull Exp Biol Med 2007a; 143: 437-441.

[18] Shabanov PD, Lebedev AA, Pavlenko VP, Ganapol'skiĩ VP. Comparative study of behavioral effects of cortexin and cerebrolysine in rats upon intraventricular and intraperitoneal administration. Eksp Klin Farmakol 2007b; 70: 13-19.

[19] Kost NV, Sokolov OY, Gabaeva MV, Zolotarev YA, Malinin VV, Khavinson VK. Effects of livagen and epitalon, new peptide bioregulators, on enkephalin-degrading enzymes from human serum. Biol Bull 2003; 30: 4 .

[20] Grigoriev EI, Kotchnev IN, Kudriavtseva TA, Grigoriev AE, Khavinson VK. New peptide immuno-modulators Vilon and Thymogen. Chemical and biophysical aspects of their action in the water medium. Proc $26^{\text {th }}$ Eur Peptide Symp Montpellier (FR) 2000; pp. 475-6.

[21] Khavinson VK. Tissue-specific effects of peptides. Bull Exp Biol Med 2001; 132: 807-8

[22] Ashmarin IP, Antipenko AE, Ashapkin VV, et al. Neurochemistry. Moscow: Inst Biomed Khim Ross Akad Med Nauk 1996; p. 470.

[23] Ganapolsky VP. Meteoadaptation genes and High Standards of Working Efficiency under Rapid Climate Changes [Russian]. Psikhofarmakol Biol Narkol (Special Edition Part 1) 2007; 7: 11652.

[24] Sollertinskaya TN, Shorokhov MV. Evolutionary Peculiarities of Regulatory and Compensatory Effects of Cortexin on Impaired Brain Function of Mammals in Ascending Sequence. Psikhofarmakol Biol Narkol (Special Edition Part 2) 2007; 7: 19578.

[25] Adriani W, Caprioli A, Granstrem O, Carli M, Laviola G. The spontaneously-hypertensive-rat as an animal model of ADHD: Evidence for impulsive and non-impulsive subpopulations. Neurosci Biobehav Rev 2003; 27: 639-51.

[26] Adriani W, Giannakopoulou D, Bokulic Z, Jernej B, Alleva E, Laviola G. Response to novelty, social and self-control behaviors, in rats exposed to neonatal anoxia: Modulatory effects of an enriched environment. Psychopharmacology 2006; 184: 155-65.

[27] Belzung C, Yalcin I, Griebel G, Surget A, Leman S. Neuropeptides in psychiatric diseases: an overview with a particular focus on depression and anxiety disorders. CNS Neurol Disord Drug Targets 2006; 5: 135-45. 